\title{
VIII
}

\section{TRAJETÓRIAS DE VIDA DE ESTUDANTES EGRESSOS DA EDUCAÇÃO DE JOVENS E ADULTOS MATRICULADOS NA EDUCAÇÃO SUPERIOR: ESTUDO DE CASO NA UNIVERSIDADE FEDERAL DO MARANHÃO*}

Werlang Cutrim Gomes ${ }^{1}$

A partir das últimas décadas do século $\mathrm{XX}$ presenciamos em diversos países da América do Sul, principalmente no Brasil, a expansão da educação superior. Foram mobilizados esforços para o desenvolvimento de políticas públicas para que sujeitos historicamente excluídos pudessem chegar à Universidade.

As políticas educacionais do Brasil de 1995 a 2016 desenvolvidas durante os governos de Fernando Henrique Cardoso (FHC), Luís Inácio Lula da Silva (Lula) e Dilma Rousseff, por exemplo, possibilitaram a expansão do número de vagas, matrículas e cursos da educação superior, inclusive do acesso a jovens e adultos das classes populares ao universo acadêmico.

Pesquisas diversas vêm sendo realizadas nos últimos anos apresentando problemas no acesso e permanência destes sujeitos nos diversos cursos das universidades brasileiras. Dentre os principais problemas, destacam-se: muitos estudantes demonstram dificuldades de adaptação ao meio acadêmico, precariedades na sua formação na educação básica, falta de recursos financeiros para as despesas básicas de sobrevivência e aquisição de materiais de estudo etc. (PEREIRA; PASSOS, 2007; PEREIRA, 2014).

Com a possibilidade de expansão da educação superior e de políticas de acesso das classes populares, os estudantes egressos da Educação de Jovens e Adultos (EJA) passaram também a conquistar uma vaga nas Instituições de Ensino Superior (IES).

Conforme pesquisas de Silva (2015), Trindade, Fernandes e Jezine (2013), Bernadim (2013), Paz e Santos (2014), Cruz (2013), etc., os egressos da EJA nos últimos anos, mesmo ainda vivenciando diversos processos de exclu-

*DOI - 10.29388/978-65-86678-41-3-0-f.173-192

${ }^{1}$ Doutor em Educação pela Universidade Federal Fluminense (UFF). Professor da Universidade Federal do Maranhão (UFMA). 
sões, buscaram superar a situação voltando a estudar, concluir a educação básica e, inclusive, ingressar em um curso superior.

Hoje, sem sombra de dúvida, é um pouco mais comum, principalmente nos cursos historicamente com maior acesso pelos sujeitos das classes populares, como os cursos de licenciaturas, encontrarmos jovens e adultos egressos da EJA matriculados em Instituições de Ensino Superior (IES) por todo o Brasil. Não é diferente o que estamos vivenciando na Universidade Federal do Maranhão.

Levando em consideração as diversas questões que envolvem hoje pensar sobre o acesso e a permanência destes sujeitos em cursos de formação superior, como professor universitário, defendi em 2019 uma tese de doutorado no Programa de Pós-graduação em Educação da Universidade Federal Fluminense que teve como objetivo analisar como os estudantes egressos da EJA que fazem curso de licenciatura na Universidade Federal do Maranhão (Campus de São Luís) conduzem sua vida acadêmica, principalmente refletindo sobre suas estratégias de acesso e permanência na universidade.

Para a realização da pesquisa, foram selecionados 8 estudantes universitários, sendo 2 de cada um dos quatro Centros de ensino (Centro de Ciências Sociais - CCSo, Centro de Ciências Humanas - CCH, Centro de Ciências Exatas e Tecnológicas - CCET e Centro de Ciências Biológicas e da Saúde - CCBS) localizados no Campus Sede da Universidade Federal do Maranhão em São Luís.

Foram realizadas entrevistas semiestruturada com estes sujeitos que estavam matriculados e cursando a partir do $2^{\circ}$ semestre letivo de 2017, com o objetivo de compreender, através de suas trajetórias de vida e acadêmica, as estratégias para acesso e permanência na Universidade.

Para análise dos dados empíricos da pesquisa, dialogamos com Bardin (1977), Danilo Martuccelli (2007a; 2007b; 2010a; 2010b), Martuccelli e Singly (2009) e Bernard Lahire (2004; 2013), principalmente com as suas reflexões sobre a sociologia em escala individual.

Procuramos, através da análise das trajetórias de vida e acadêmica dos sujeitos da pesquisa, em linhas gerais, compreender quais foram as "provas" e "suportes" enfrentados pelos estudantes no seu dia a dia para prosseguirem e concluírem o curso superior em que estão matriculados. Destacamos ainda as disposições desenvolvidas durante o processo de socialização vivenciado nas suas trajetórias de vida, desvelando as ações de individuação. 
Diante de tais questões, este artigo, em linhas gerais, ciente da importância e complexidade da discussão, tem como objetivo contribuir com o debate sobre políticas de acesso e permanência na educação superior no Brasil.

\section{Expansão da educação superior no Brasil}

A educação superior no Brasil passa por significativa expansão a partir da Constituição Federal de 1988, que garante a obrigação do Estado para assegurar educação para todos, inclusive o acesso e a permanência. Para uma maior compreensão da expansão da educação superior no Brasil apresentamos abaixo dados do número de IES, cursos de graduação e matrículas fornecidos pelo Instituto Nacional de Estudos e Pesquisas Educacionais Anísio Teixeira - INEP nos três governos em discussão (1996 a 2015).

A quantidade de IES públicas nos dois mandatos do Governo de FHC diminuiu 7,1\% devido a aglutinação de algumas delas. Por outro lado, o setor privado obteve um aumento da ordem de $52,5 \%$.

No último ano do Governo Lula, o número de IES do setor público aumentou $29,8 \%$ e do setor privado $31,3 \%$ em relação ao Governo de Fernando Henrique Cardoso. O Governo de Dilma Rousseff aumentou o número de IES públicas em $6 \%$ e o setor privado em $0,5 \%$ em relação ao Governo de Lula.

Nos governos Lula e Dilma Rousseff, ao contrário do governo FHC, foram instituídas novas Universidades e Instituições Federais de Educação Superior (IFES) havendo um aumento considerável no número de IES públicas.

Com relação à quantidade de cursos superior de graduação, no governo FHC houve um aumento total na ordem de $56,5 \%$, sendo $47 \%$ no setor público e $62 \%$ no privado. A diferença da quantidade de cursos do setor privado em relação ao público foi de $15 \%$.

O último ano do governo Lula apresentou um aumento na quantidade de cursos de graduação, incluindo-se os realizados a distância. No setor público houve aumento de $43,1 \%$ e no privado de $54,8 \%$ em relação ao Governo de FHC.

O governo de Dilma Rousseff, comparando os dados do governo Lula, no último ano de mandato, apresentou um aumento de 12,3\% nos cursos de graduação, incluindo-se os de educação a distância no setor público. O setor privado resultou em um aumento de 14,9\%. 
O número de matrículas nos três Governos também aumentou, principalmente no setor privado. No Governo FHC houve um aumento de 49,4\%, sendo 33,3\% no setor público e 56,3\% no privado. A diferença do setor privado para o público foi de $23 \%$.

No último ano do Governo Lula, comparado ao de FHC, apresentou um aumento no setor público de $28 \%$ e no privado de $39,1 \%$.

O último ano do governo de Dilma Rousseff, considerando matrículas nos cursos de graduação nas modalidades presenciais e a distância, o setor público aumentou $26,5 \%$ e o privado $34,1 \%$ em relação ao Governo Lula.

Quanto à Pós-Graduação no Governo FHC, durante a década de 1990 as matrículas expandiram-se, porém, a quantidade das bolsas de pesquisa foi reduzida proporcionalmente.

De acordo com Velloso (2000), dos anos 1994 em diante, aumentou o número de mestrandos em $25 \%$ e de doutorandos em $50 \%$. Contudo, "o número de bolsas concedidas não seguiu essa tendência". Iniciou-se um processo de redução das bolsas de pesquisas científicas para os Programas de Pós-Graduação (VELLOSO, 2000, p. 89).

Somente no Governo de Lula, após 19 anos do último Plano para a pós-graduação no Brasil, que é apresentado o novo Plano Nacional de PósGraduação (PNPG) abrangendo o período de 2005 a $2010^{2}$.

Conforme Siqueira (2006), o PNPG (2005 - 2010) destaca dentre outras questões, que o sistema educacional é fator estratégico para o desenvolvimento socioeconômico e cultural; que deve ter como objetivos formar recursos humanos qualificados; fortalecer o potencial científico e tecnológico do país modernizando-o (SIQUEIRA, 2006).

Durante o Governo Dilma Rousseff, o número de Programas de PósGraduação cresceu 25\% nos últimos quatro anos.

A discussão sobre a expansão da educação superior requer um aprofundamento que envolve não apenas a quantidade de IES, cursos, vagas e matrículas neste nível de ensino. Também exige uma análise sobre as demais categorias que estão relacionadas principalmente com as matrículas e os estudantes.

\footnotetext{
${ }^{2}$ Com base nas portarias Capes no 46, de 19/05/04; n ${ }^{\circ} 53$, de 22/06/04, e no 83, de 29/09/04 foi constituída uma Comissão para a elaboração do Plano Nacional de Pós-Graduação (PNPG 2005 - 2010). A Comissão foi formada pelos representantes do Conselho Superior da Capes, por indicados pela Diretoria-Executiva da Capes, por representante do Conselho Nacional de Desenvolvimento Científico e Tecnológico (CNPq), da Financiadora de Estudos e Projetos (Finep), e pelos presidentes do Fórum de Pró-Reitores de Pesquisa e Pós-Graduação das Instituições Brasileiras (Forprop) e da Associação Nacional de Pós-Graduandos.
} 
Houve um aumento real no número de matrículas dos cursos de graduação: bacharelado $34,2 \%$; licenciatura 49,2\% e os cursos de tecnólogo aumentaram $48,5 \%$.

O aumento total de matrículas em cursos de graduação (todos os cursos) nas IES, no período de 2009 a 2016 para o Brasil foi de 36,4\%. Sobressaiuse os cursos de licenciatura, seguido dos tecnólogos.

Os estudantes procedentes de escolas públicas matriculados nas IES em cursos de graduação presencial e a distância somaram um total de 70,8\% no período de 2011 a 2016. Aqueles que fizeram a educação básica em escolas particulares contabilizaram 54,2\%. Segundo esses dados, ganha importância a escola pública garantindo a entrada das classes populares na educação superior.

Quanto ao quantitativo de estudantes matriculados em cursos de graduação nas modalidades presencial e a distância no período de 2011 a 2016 por faixa etária, foi possível observar que houve um aumento de $24,2 \%$ dentre os que possuíam de 35 a 39 anos. Também foi constatado que as gerações com idade acima dos 40 anos em diante se fizeram bastante representados e na faixa etária de 50 a 54 anos presenciamos um aumento de $17,3 \%$.

O número de matrículas para os estudantes do sexo masculino aumentou em $16,4 \%$ e os do feminino em $17,1 \%$. As mulheres são em maior número nos cursos de graduação.

Quanto às matrículas nos cursos de graduação, observando-se a auto declaração de cor ou raça, houve um aumento no Brasil de 53,3\% no número de estudantes brancos e de $66,8 \%$ de estudantes pretos. Os pardos aumentaram em $66,4 \%$. Também há uma grande representação quanto aos que se autodeclararam indígenas, o aumento foi de 80,1\%.

Os portadores de necessidades especiais também estão bem representados nos cursos de graduação das IES, pois temos um aumento de matrícula da ordem de 35,2\% no período de 2011 a 2016.

Conforme Dias Sobrinho (2011), a expansão do sistema de ensino superior ocorre em um contexto instável e de transformações. Incluem-se as amplas e profundas transformações contextuais, destacando-se os processos de migração urbana; modernização e globalização da economia, com reflexos importantes no mundo do trabalho; mudanças culturais impulsionadas pelos sistemas de informação, destacando-se, por exemplo, a ascensão social das mulheres e o valor do conhecimento como fonte primária do desenvolvimento. 
A ampliação da educação superior vem gerando dificuldades administrativas e pedagógicas para a qualidade da educação. Com a ampliação da rede de educação superior, cresce o número de instituições e se fragmenta o sistema.

A relação do público com o privado não tem sido bem definida e a comunicação entre ambos está cada vez mais próxima. O financiamento exige novos modelos devido à grande expansão de Instituições de Ensino Superior.

São desenvolvidos novos programas de financiamento como ações afirmativas consignadas em cotas e a renúncia fiscal para as empresas do setor educacional. O Estado por não ter capacidade de prover a educação superior, atendendo à grande demanda, desenvolveu uma política de expansão via iniciativa privada. As instituições se diversificaram, concorrem as instituições públicas e privadas pela demanda de estudantes à educação superior.

Dias Sobrinho (2011, p. 141) observa que "a expansão do sistema tem contribuído muito para a democratização da educação superior e para uma maior inclusão social, embora ainda mantenha suas marcas de elitismo".

O Brasil se apresenta em uma situação bastante inferior em relação aos outros países com um mesmo nível de desenvolvimento ou com maior nível de pobreza. Embora a educação tenha se expandido cada vez mais a partir do final do século XX, chegando a um segmento populacional anteriormente excluído deste espaço, ainda presenciamos indicadores de acesso e permanência muito negativos.

Infelizmente, embora crescido o número real de matrículas e cursos, grande parte da população brasileira continua sem acesso à educação superior. O crescimento ainda é muito insignificante se comparado com os dados de países da América do Sul, América do Norte, América Latina, Ásia e Europa (RISTOFF, 2011).

Com o advento da expansão da educação, as classes populares têm conseguido maior acesso às universidades para realizar a sua formação em nível superior. Nos últimos anos, evidenciamos que algumas políticas de governo têm favorecido pessoas historicamente excluídas do acesso à educação para continuar seus estudos, alcançando inclusive a universidade. Contudo, a inclusão na educação superior de pessoas historicamente excluídas requer maiores reflexões considerando-se as políticas de ajuste neoliberal. 


\section{Acesso e permanência de estudantes de classes populares na Edu- cação Superior no Brasil}

A questão do acesso à educação ainda não está resolvida e os problemas que afetam a permanência dos estudantes no meio educacional também pedem soluções do poder público. Muitos estudantes têm dificuldades de acesso à universidade; participar das diversas atividades acadêmicas e ainda enfrentam problemas financeiros. Há aqueles com educação básica precária; sentem dificuldades para estudar e fazer as tarefas solicitadas pelos professores.

Dentre estes estudantes, alguns são egressos da Educação de Jovens e Adultos (EJA). As pesquisas realizadas sobre estudantes universitários oriundos da Educação de Jovens e Adultos (BERNADIM, 2013; CRUZ, 2013; PAZ; SANTOS, 2014; SILVA, 2015; ARAÚJO; TRINDADE; FERNANDES, 2013), identificam diversas questões, tais como: acesso e permanência à universidade; exclusão da educação básica; influência e apoio da família e amigos na formação do estudante; valor atribuído ao curso que está fazendo na universidade e perspectivas de futuro profissional.

O acesso e permanência do estudante universitário na universidade nos remete a buscar compreender esta organização institucional historicamente. Compreender a universidade brasileira, principalmente a pública, implica percebê-la dentro de um contexto amplo e estrutural.

Se a Universidade está cada vez mais possibilitando a estudantes de classes populares fazer um curso superior, importa tomar ciência a qual lugar eles estão sendo destinados. A expansão se apresenta diferenciando-se conforme as classes sociais.

Sobre a expansão da educação superior foram identificadas, dentre outras, contradições que são inerentes à própria sociedade brasileira, por exemplo, a hierarquização de cursos superiores.

[...] encontramos no plano superior as chamadas "profissões imperiais": Medicina, Direito e Engenharia. E no plano médio ou inferior, carreiras relacionadas às Licenciaturas. Pode-se dizer que o prestígio das carreiras se forma pelo agregado de seu valor simbólico e de mercado, refletindo em cursos de acesso mais disputado (VARGAS, 2010, p. 5).

O que presenciamos é uma expansão da educação superior que oferece: "curso de rico pra continuar rico e curso de pobre pra continuar pobre" (VARGAS, 2010, p. 1), pois, as classes populares se encontram em maior número 
nos cursos de licenciatura, enquanto a classe abastada ocupa as vagas dos cursos que os levam a profissões mais valorizadas no Brasil.

Os estudantes universitários que chegam ao curso de licenciatura são, em sua maioria, de classes populares e com menor poder aquisitivo. Comumente encaram problemas para permanecer na universidade e alcançar a formação. Por falta de recursos financeiros, apresentam dificuldades de acesso à universidade e participação em atividades acadêmicas. Ainda, alguns apresentam formação precária de educação básica, dificuldades para estudar e desenvolver as tarefas das disciplinas, assim como se envolver nas diversas atividades acadêmicas da universidade.

Conforme Zago (2006), não é suficiente ter acesso à educação superior, é preciso garantir também a permanência dos estudantes. Diversos são os problemas que estes enfrentam quando chegam à universidade dificultando a permanência no meio acadêmico. A permanência dos estudantes de classes populares na educação superior requer programas de assistência estudantil.

$\mathrm{O}$ acesso e a permanência de estudantes de classes populares na universidade ainda são desafios a serem enfrentados pelos que procuram realizar estudos em nível superior.

\section{Compreendendo as trajetórias de vida e acadêmica dos estudantes egressos da educação de jovens e adultos}

Consideramos para análise dos dados coletados na pesquisa os aspectos ligados às dimensões: faixa etária, aspectos pedagógicos, a família e o trabalho. Cabe observar, de acordo com Lahire (2004), que a ideia de disposição remete à ação cognitiva demonstrando opiniões, práticas e coerências no comportamento, porém, nos diversos momentos da vida, não se desenvolvem de forma geral e ativa. A coerência tem relação com a delimitação das áreas de pertinência, classes de contextos e atualização da disposição reconstruída. A transferibilidade de disposição ou esquema é relativa, desenvolve-se a partir do contexto mais próximo em conteúdo e estrutura do contexto de origem; a transferência ocorre quando os contextos são diferentes. Se a situação é repetitiva, não há transferência.

Os sujeitos entrevistados estão na faixa etária entre 27 a 32 anos, ou seja, jovens adultos. Segundo Léon (2005, p. 10), os conceitos adolescência, juventude, adultos e idoso, “[...] correspondem a uma construção social, histórica, 
cultural e relacional, que através das diferentes épocas e processos históricos e sociais vieram adquirindo denotações e delimitações diferentes".

Analisando o perfil etário dos sujeitos entrevistados, todos são jovens, corroborando com a discussão hoje em pauta que afirma ter mudado nas últimas décadas o perfil dos sujeitos da EJA. Observa-se que tem aumentado o número de jovens nesta modalidade de ensino.

Ao contrário do perfil dos antigos estudantes da EJA, que iniciaram o seu processo de escolarização direto na EJA, todos os entrevistados tiveram a oportunidade de ingressar em uma escola regular quando criança, mas, por motivos diversos, tiveram que parar de estudar em algum momento da sua vida: gravidez precoce, não entendia os conteúdos e as explicações dos professores, precisou cuidar da mãe doente, por constantes reprovações, precisou trabalhar para ajudar no sustento da família, por ter ficado doente e por resolver ingressar imediatamente no mundo do trabalho.

A análise de conteúdo (Bardin, 1977), revelou nas respostas às entrevistas realizadas com os estudantes que participaram da pesquisa em questão, que há grande preocupação em conciliar estudo e trabalho, fazem um esforço além do possível para seguirem com os estudos.

Analisando as trajetórias de vida e escolar dos sujeitos entrevistados, é possível perceber que trazem em sua biografia uma origem muito parecida: são todos de classe popular, começaram a trabalhar muito cedo e frequentaram a EJA depois de algum tempo desligados da educação básica regular. No entanto, ao contrário de muitos estudantes da EJA, tiveram um contexto social diferenciado, pois desenvolveram singularidades que os levaram até a educação superior.

Buscando compreender estes traços singulares que os levaram a pensar sobre a possibilidade de seguirem estudando em um curso superior, analisamos como estes sujeitos construíram os seus patrimônios de disposições, experiências e socialização.

Lahire (2004) sugere que se faça uma abordagem mais complexa desvendando as múltiplas dimensões que os constitui como sujeitos, principalmente procurando compreender como se realizou o processo de socialização.

Foi observado na história de vida dos sujeitos entrevistados, que todos vivenciaram processos de individuação muito particular com experiências de socialização diferenciadas.

O trabalho, compreendido com atividade laboral remunerada, é uma condição presente na vida de todos os entrevistados. Ter que trabalhar jovem 
não é apenas um desejo, mas sim uma necessidade e condição para a sobrevivência deles e da família.

Por diversos motivos, retornaram aos estudos, procuraram a EJA e começaram a pensar na possibilidade de seguir para a educação superior. A grande maioria afirma ter voltado a estudar por orientação e incentivo de amigos e familiares e identificam nos estudos a possibilidade de um futuro profissional e social melhor.

Sobre a escolha do curso, através das suas experiências pessoais, cada um apresentou motivo diferente, destacando-se: desejar ser professora, querer ser secretária, ter gostado dos assuntos da área de geografia que o professor abordava, conhecer melhor a história humana, por gostar de cálculos e desejar se aperfeiçoar na área, sonhar com um emprego melhor, defender a natureza e interesse pela prática de esportes.

O motivo que levou a maioria dos entrevistados a escolher um curso superior está relacionado ao campo de trabalho. Muitos já tiveram algum contato com o mundo do trabalho no qual o curso se insere. Alguns depoimentos também remetem a sua escolha a fatores sociais e de busca de qualidade de vida.

É possível perceber nas respostas dos entrevistados que todos vivenciaram várias "provas" e "suportes" nas suas trajetórias de vida. Dentre as principais "provas", no caso das mulheres, a gravidez na adolescência se apresenta como uma importante questão que provocou mudanças sérias nas suas trajetórias de vida, impedindo muitas vezes que seguissem estudando.

A necessidade de trabalhar ainda jovem é outra questão muito presente na vida destes sujeitos. $\mathrm{O}$ trabalho é uma condição para ajudar na sobrevivência da família, passando a ser prioridade na vida.

Também aparece nas falas dos entrevistados que o não sucesso no processo de escolarização, acabou sendo importante prova para decidir parar de estudar.

Conforme o Instituto Brasileiro de Geografia e Estatística, na Pesquisa Nacional por Amostra de Domicílios 2012 (IBGE - PNAD 2012), a taxa de frequência bruta a estabelecimentos de ensino da população residente segundo grupos de idade em 2011, na faixa etária de 6 a 14 anos, alcançou a marca de $98,2 \%$. Por outro lado, na faixa etária entre 15 a 17 anos, foi de $83,7 \%$. Através destes dados é possível identificar que muitos jovens tiveram acesso à escola na idade certa, mas deixam de estudar simplesmente quando saem da faixa etária de escolarização considerada obrigatória por nossa legislação. 
Evidenciamos que desde a década de 1990, cresceu a taxa da frequência bruta a estabelecimentos de ensino na faixa etária considerada obrigatória pela nossa legislação. Por outro lado, em virtude do não sucesso no seu processo de escolarização, muitos alunos vão ficando retidos ao longo dos anos e sendo muitas vezes "expulsos" - convidados pela direção da escola a frequentar a EJA quando completam 15 anos e ainda estão no ensino fundamental.

Permanecer estudando na EJA também é algo relatado pelos entrevistados como muito difícil, visto que precisam estudar e trabalhar. A condição de estudante trabalhador é algo apresentado como importante "prova" na vida desses sujeitos. São obrigados a pensar em estratégias diversas para sobreviver estudando e trabalhando ao mesmo tempo. Muitos relatam, inclusive, deixar de viver momentos de lazer. Toda folga no trabalho é transformada em momentos de estudo.

Para muitos, são nestes momentos de "folga do trabalho" que efetivamente conseguem dar conta das atividades acadêmicas previstas nos estudos. Sem elas, os estudos estariam mais comprometidos.

Reconhecem que para se manterem estudando, vale todo o esforço pessoal, inclusive deixando de viver momentos de lazer e de folga do trabalho.

A escola de educação básica para alguns entrevistados foi considerada inadequada: fraca quanto ao ensino; não havia muita diferença na forma de ensinar do ensino regular para a EJA; não se levava em consideração o fato de já terem uma idade mais madura (jovens ou adultos) e que muitos já trabalhavam ou já possuíam responsabilidades familiares.

Embora estudar à noite na EJA seja "prova" para os sujeitos entrevistados, pois é difícil conciliar o trabalho e o estudo, por outro lado, quase todos sinalizaram ser um importante "suporte".

Para muitos foi uma importante experiência, principalmente porque os possibilitou aprendizagens sociais diversas com sujeitos mais experientes.

Muitos também conseguiram superar as dificuldades no processo de ensino aprendizagem na relação com os seus colegas de classe. Relatam que conseguiram através dos seus colegas tirar dúvidas e compreender melhor os conteúdos das disciplinas.

Lahire (2004) observa que as conversas e as vivências são importantes para a socialização dos sujeitos, decidindo as singularidades e as trajetórias de vida.

Em virtude das questões vivenciadas no cotidiano de sala de aula da EJA em que as diversas gerações estão geralmente presentes (jovens, adultos e 
idosos) em uma mesma turma, é comum se reconhecer como solução para os conflitos geracionais, separarem as turmas por faixa etária. É muito comum se justificar, por exemplo, a manutenção de turmas somente de jovens separados dos adultos e idosos.

Observando o apresentado pelos entrevistados sobre a importância de conviver com sujeitos mais experientes, põe em questionamento a prática de separação das turmas por faixa etária. Ratifica as motivações defendidas por alguns profissionais da área de EJA que afirmam que a presença de gerações diversas na mesma sala de aula é muito mais enriquecedora do que prejudicial ao processo educativo.

Para Lahire (Ibidem, p. 17) há uma disposição moral, as pessoas se ajudam mutuamente diante das dificuldades estruturais. Observa que: "a estrutura e a forma do comportamento de um indivíduo dependem da estrutura de suas relações com os outros indivíduos".

Embora reconheçamos que a gravidez precoce tenha sido "prova" para algumas das jovens entrevistadas na pesquisa, por outro lado, também podemos considerar como "suporte", visto que a condição de ser mãe gerou disposição para buscar um futuro melhor para os seus filhos.

Chegar à universidade para os sujeitos entrevistados foi sem dúvida uma grande conquista pessoal e social. Muitos são os primeiros da sua família a alcançar tal feito. Por outro lado, permanecer e concluir os seus estudos, vivenciar a vida acadêmica não é nada fácil. Precisam cotidianamente superar barreiras. Muitas delas vivenciadas antes, quando ainda estavam estudando na EJA: estudar e trabalhar concomitantemente, tempo para se dedicar aos estudos, cumprir com as atividades acadêmicas etc.

Levando em conta a vida dos entrevistados hoje na universidade, várias são as "provas" e "suportes" vivenciados cotidianamente para sobreviverem no ensino superior, destacando-se, dentre outros: o processo de ensino-aprendizagem dos conteúdos das disciplinas, a metodologia de ensino e avaliação, a participação e realização das atividades acadêmicas, a realização do estágio, a relação com os seus colegas de classe, o apoio de familiares e amigos, a compreensão de seus chefes no trabalho etc.

Ter que se desdobrar entre trabalhar e estudar, evitar perder aulas e estar sempre atualizado com os conteúdos das disciplinas são verdadeiras "provas" para sobrevivência na universidade.

Os entrevistados vivenciam uma carga de trabalho pedagógico intensa nos cursos e nem sempre podem acompanhar todas as atividades previstas para 
o seu desenvolvimento profissional, como é o caso dos eventos acadêmicos e científicos. Assim, priorizam a participação em sala de aula, procurando não faltar às aulas e sempre estar atualizados com os conteúdos das disciplinas.

Consideram que sentem mais dificuldades em acompanhar os conteúdos das disciplinas por terem estudado na EJA. Muitos professores, segundo eles, não levam em consideração estas questões; que alguns alunos são egressos da EJA e/ou fizeram cursos técnicos no ensino médio. Ou seja, não tiveram acesso a todos os conteúdos previstos na educação básica regular com profundidade.

Afirmam ainda que a maioria dos professores não reconhece que muitos alunos hoje, que estão cursando a universidade, são alunos trabalhadores. Então, reclamam que há uma sobrecarga de atividades que acaba dificultando a realização do curso.

Por saírem direto do trabalho para ir à universidade e dependerem de transporte coletivo (ônibus), queixam-se de um cotidiano muito agitado. Geralmente chegam atrasados e cansados nas aulas.

Sempre são prejudicados nas atividades acadêmicas e administrativas da universidade. Por exemplo, não conseguem jantar no Restaurante Universitário da UFMA. Quando decidem por jantar, chegam pela metade da aula.

Outro problema apresentado pelos entrevistados, é na hora de retornar para casa. Muitos afirmam não ter transporte coletivo suficiente à noite, o Campus da UFMA fica vazio, com pouca iluminação e segurança.

A universidade (UFMA) não é percebida pelos entrevistados como acolhedora. Reclamam não existir ambientes de convivência para os estudantes. Geralmente precisam esperar os horários de aulas nos corredores, nas cantinas ou nas bibliotecas. São espaços cheios, com estudantes conversando alto e com muito barulho.

Reclamam ainda dos espaços destinados ao serviço de cópias (Xerox), pois são espaços pequenos e muito inadequados, não comportando a quantidade de estudantes que procuram pelo serviço. Às vezes, deixam para tirar cópia dos textos em outro momento, pois, o espaço destinado a este serviço fica muito lotado de estudantes. Infelizmente, alguns só podem tirar cópia na parte da noite.

Os entrevistados também reclamam dos setores administrativos da universidade, pois muitos não funcionam na parte da noite. Quando funcionam, faltam funcionários para o atendimento adequado. 
Deixaram transparecer certa decepção com relação ao que esperavam encontrar na Universidade. Acreditavam que pelo fato de a UFMA ser uma instituição federal, teria uma melhor infraestrutura e seria mais organizada e preparada para atender a todos os estudantes, inclusive os que estudam na parte da noite.

Por não terem estado antes na universidade, quando ainda estavam estudando na educação básica, geralmente a imaginavam como um espaço de excelência e completamente diferente do que vivenciam agora no seu cotidiano enquanto estudantes.

Cada entrevistado vivencia estratégias diferentes para sobreviver na universidade. Como podemos observar, desenvolver disposição de estudante não é fácil para os que são também trabalhadores, principalmente para os egressos da EJA. Precisam cada vez mais se desdobrar no seu cotidiano para sobreviverem no mundo do trabalho e continuar estudando.

Muitos relataram que o convívio com os colegas de classe é uma importante estratégia de sobrevivência no curso e na universidade. São os colegas de classe que geralmente os ajudam, atualizando-os sobre as matérias que não puderam acompanhar, bem como ajudando na realização de trabalhos de grupos e tirando dúvidas sobre os conteúdos. Assim, vão conseguindo maturidade para seguir aprendendo e viver o cotidiano acadêmico da Universidade.

A partir dos relatos dos estudantes entrevistados inferimos que as disposições identificadas na dimensão aspectos pedagógicos não significam respostas do tipo estímulo mecânico e simples, trata-se de uma maneira de olhar, sentir e agir que vai se ajustando de forma flexível aos diversos contextos ou situações com que o indivíduo se depara. Pode haver disposição que não se adapta, ela pode ser transformada em consequência de sucessivos reajustes congruentes e pode ser inibida ficando em estado de vigília (LAHIRE, 2004).

Lahire (Ibidem) observa que o olhar microssociológico favorece a descoberta da relativa heterogeneidade do que pensamos ser homogêneo: determinado meio social ou familiar. As redes de interdependência com sua relativa instabilidade, os aspectos contraditórios, destacando-se princípios de socialização concorrentes que são observados em uma abordagem microssociológica.

A dimensão família traz novas disposições para compreendermos os sujeitos da pesquisa - os estudantes egressos da EJA que fazem curso de licenciatura na UFMA. Conforme Lahire (Ibidem,2004), o indivíduo, ao desenvolver relações de interdependências com os familiares, não as reproduz exatamente como foram apreendidas, no entanto, as faz com um estilo próprio. Por isso, 
compreendemos a importância da família no processo de constituição dos sujeitos, mas também entendemos que podem ser determinantes para buscas de caminhos diversos, muitas vezes em oposição aos ensinamentos e tradições familiares às vezes impostas.

A família, segundo Lahire (Ibidem, p. 25-26), “[...] pode constituir um 'lugar decente', um tipo de santuário de ordem, de ordenação, relativamente fechado sobre si mesmo, para evitar as influências nefastas, os possíveis 'desvios estranhos' [...]".

As famílias dos entrevistados apresentam uma composição muito singular de uma família tradicional de classe popular: quatro pais são funcionários públicos, dois comerciantes, um trabalha em empresa particular, um é feirante, um comerciário e três mães "cuidam do lar".

Quanto à sua formação educacional, seis terminaram a educação básica, sete somente fizeram o ensino fundamental, e uma fez curso superior de enfermagem. Dentre os entrevistados, temos apenas um que é filho único, os demais têm irmãos. Apenas um entrevistado é filho de pais separados. Os dados desta pesquisa nos levam a refletir que estamos diante de uma elite de classe popular.

Compreendemos que a estrutura familiar é fundamental para constituição do sujeito. O papel da família, por exemplo, possibilita muitas explicações sobre o sucesso ou fracasso escolar. Conforme Lahire (Ibidem, p. 26), “[...] moral do bom comportamento, da conformidade às regras, moral do esforço, da perseverança, são esses os traços que podem preparar, sem que seja consciente [...] uma boa escolaridade".

Ainda de acordo com Lahire (Ibidem, p. 28), “[...] as diferentes formas de exercício da autoridade familiar dão relativa importância ao autocontrole e à interiorização das normas de comportamento".

Analisando as trajetórias escolares dos entrevistados, é possível se evidenciar que a família foi importante tanto para o seu sucesso escolar como para o seu fracasso. Por conta da família, alguns sujeitos foram obrigados a parar de estudar. Por outro lado, também foi por conta do apoio familiar que voltaram a estudar e seguiram até a Universidade.

\section{Considerações finais}

A partir dos relatos obtidos por meio das entrevistas com os estudantes da UFMA que são egressos da EJA foi possível desvelar suas trajetórias de vida, compreender as provas, suportes e disposições que enfrentam para realizarem- 
se nos estudos. Foi possível observar que há uma "pluralidade" de realidades sociais permeando a biografia dos entrevistados (Lahire, 2004).

Os entrevistados são sujeitos comuns de classe popular. Inseridos no seu tempo, vivenciam diversos problemas que fazem parte da realidade de muitos cidadãos brasileiros na sociedade contemporânea.

Todos os entrevistados têm enfrentado provas em suas trajetórias de vida e recebido importantes suportes de amigos ou familiares. Assim conseguem viver, interagindo na sociedade e obtendo sucesso no seu processo educacional, principalmente buscando alcançar os seus objetivos e projetos de vida que sonharam um dia.

Através das narrativas de vida, os entrevistados refletiram sobre suas dificuldades ou provas e conseguimos juntos perceber que conciliar estudo e trabalho é algo muito complexo e difícil. É uma prova na trajetória de vida.

A presença da família, de algum familiar ou amigo foi fundamental na constituição de suporte para os sujeitos entrevistados. Foi possível se identificar no processo de individuação destes sujeitos a relação dialética com as estruturas da sociedade. Relações que singularizam cada um dos sujeitos participantes desta pesquisa.

A relação trabalho e estudo é uma das condições fundamentais para a compreensão destes sujeitos. Nesse sentido, sobrevivem pensando em estratégias para seguir com os seus objetivos: seja buscando o apoio para a mudança no horário das atividades laborativas ou solicitando a compreensão por parte dos professores por não conseguirem chegar no horário de início das aulas e muitas vezes não cumprir com as atividades planejadas.

Através das histórias de vida dos entrevistados foi possível perceber a luta pela sobrevivência e a crença na educação como fator de emancipação econômica e social. As narrativas estão permeadas do desejo de superar as dificuldades sociais e alcançar os seus objetivos pessoais.

Escutando os estudantes, participantes desta pesquisa, foi possível construir um quadro social que nos ajuda a compreender melhor como vivenciam no seu cotidiano estes jovens e adultos das classes populares que hoje conquistaram o direito de estar nos bancos escolares das universidades públicas brasileiras. Sem sombra de dúvida, são trajetórias que nos ajudam a refletir sobre a necessidade de políticas que vão além propriamente de incentivos para ter acesso ao ensino superior. É fundamental que as universidades públicas invistam em políticas que possibilitem a permanência destes sujeitos nos espaços es- 
colares. Caso contrário, poderão ser usados como justificativas para o fracasso da inserção das classes populares no universo acadêmico.

\section{Referências}

ARAUJO, E. J. M.; TRINDADE, C. R. P. B. da.; FERNANDES, J. G. Perfil e trajetórias históricas dos alunos advindos da EJA no curso de pedagogia na UFPB. In: COLÓQUIO INTERNACIONAL DE PESQUISAS EM EDUCAÇÃO SUPERIOR - POLÍTICAS DE INCLUSÃO E IGUALDADE SOCIAL, 2013, João Pessoa. Anais ... João Pessoa: Editora da UFPB, 2013.

BARDIN, L. Análise de conteúdo. Lisboa: Edições 70, 1977.

BERNADIM, M. L. Educação e trabalho na perspectiva de egressos do ensino médio e estudantes universitários. Nuances: estudos sobre educação, São Paulo, v. 24, n. 1, p. 200-217, jan./abr. 2013.

BRASIL. Constituição (1988). Constituição da República Federativa do Brasil. Brasília: Congresso Nacional, 1989.

. Coordenação de aperfeiçoamento de pessoal de nível superior - CAPES. Portarias Capes n ${ }^{\circ}$ 46, de 19 de maio de 2004; n ${ }^{\circ}$ 53, de 22 de junho de 2004, e n ${ }^{\circ} 83$, de 29 de setembro de 2004. Institui Comissão para a elaboração do Plano Nacional de Pós-Graduação (PNPG 2005 - 2010).

. Instituto Nacional de Estudos e Pesquisas Educacionais Anísio Teixeira. Censo da educação superior. Disponível em:

$<$ http://portal.inep.gov.br/web/guest/censo-da-educacao-superior $>$. Acesso em: 2 out. 2016.

. Instituto Brasileiro de Geografia e Estatística. Pesquisa nacional por amostra de domicílios 2012. Rio de Janeiro: IBGE, versão online. Disponível em: <https://www.ibge.gov.br/>. Acesso em: 6 mai. 2018.

CRUZ, N. C. da. A inserção de egressos/as da Educação de Jovens e Adultos no Ensino Superior Público, no estado da Bahia e as condições de permanência. In: REUNIÃO ANUAL DA ASSOCIAÇÃO NACIONAL DE PESQUISADORES DOCENTES, 11., 2013, São João Del Rei. Anais... São João Del Rei: ANPED, 2013.

DIAS SOBRINHO, J. Educação superior: democratização, acesso e permanência com qualidade. In: PAULA, M. de F. C. de.; LAMARRA, N. F. (org.). Re- 
formas e democratização da educação superior no Brasil e na América Latina. Aparecida: Ideias \& Letras, 2011, p. 141.

LAHIRE, B. Sucesso escolar nos meios populares: as razões do improvável. São Paulo: Ática, 2004.

Dans les plis singuliers du social: individus, institutions, socialisations. Paris: Éditions La Découverte, 2013.

LEÓN, O. D. Adolescência e juventude: das noções às abordagens. In: FREITAS, M. V. de. Juventude e adolescência no Brasil: referências conceituais. São Paulo: Ação educativa, 2005, p. 10.

MARTUCCELLI, D. Lecciones de sociologia del individuo. Cuaderno de trabajo, Peru, n. 2, v. 1, p. 1-156, ago. 2007a.

Cambio de rumbo. Santiago: LOM Ediciones, 2007b.

La individuación como macrosociología de la sociedade singularista.

Persona y sociedade, Santiago, v. 24, n. 3, p. 9-29, dez. 2010a. Disponível em: $<$ http://repositorio.uahurtado.cl/handle/11242/218>. Acesso em: 16 out. 2011.

Exiten indivíduos en el Sur? Santiago: Ed. LOM, 2010b.

MARTUCCELLI, D.; SINGLY, F. Sociologies contemporaines: les Sociologies de l'individu. Espagne: Armand Colin, 2009.

PAZ, S.; SANTOS, M. de L. dos. O ingresso de alunos egressos da EJA no curso de pedagogia da UFGD - turma de 2013. In: ENCONTRO DE ENSINO, PESQUISA E EXTENSÃO, 8., encontro de pesquisa e extensão, 5., 2014, Mato Grosso do Sul. Anais ... Mato Grosso do Sul: ENEPEX UFGD; EPEX UEMS, 2014.

PEREIRA, S. C.; PASSOS, G. de O. Desigualdade de acesso e permanência na universidade: trajetórias escolares de estudantes das classes populares. Linguagem, Educação e Sociedade, Teresina, ano 12, n. 16, p. 19 - 32, jan./jun. 2007.

PEREIRA, T. I. Classes populares na universidade pública brasileira e suas contradições: a experiência do Alto Uruguai Gaúcho. 2014. Tese (Doutorado em Educação) - Faculdade de Educação, Universidade Federal do Rio Grande do Sul, Porto Alegre, 2014, p. 252. 
RISTOFF, D. A expansão da educação superior brasileira: tendências e desafios. In: PAULA. M. de F. C. de; LAMARRA. N. F. (org.). Reformas e democratização de educação superior no Brasil e na América Latina. Aparecida: Editora Ideias \& Letras, 2011.

SILVA, N. da. Processo de afiliação de egressos da EJA no ensino superior: desafios e propostas à docência universitária. Revista Brasileira de Educação de Jovens e Adultos, Salvador, v. 3, n. 5, p. 121-147, 2015.

SIQUEIRA, Â. C. de. O Plano Nacional de Pós-Graduação 2005 - 2010 e a reforma da educação superior do governo Lula. In: SIQUEIRA, Â. C. de.; NEVES, L. M. W. (org.). Educação superior: uma reforma em processo. São Paulo: Xamã, 2006, p. 108.

TRINDADE, C. R. P. B. da.; FERNANDES, J. G.; JEZINE, E. Perfil e trajetórias históricas dos alunos advindos da EJA no curso de pedagogia na UFPB. In: COLÓQUIO INTERNACIONAL DE PESQUISAS EM EDUCAÇÃO SUPERIOR, 1., 2013, João Pessoa. Anais... João Pessoa: UFPB, 2013.

VARGAS, H. M. Aqui é assim: tem curso de rico pra continuar rico e curso de pobre pra continuar pobre. In: REUNIÃO ANUAL DA ASSOCIAÇÃO NACIONAL DE PESQUISADORES DOCENTES, 33., 2010. Caxambu. Anais ... Caxambu: ANPED, 2010.

VELLOSO, Jacques. A formação de cientistas: necessidades e soluções. In: SCHMIDT, B. V.; OLIVEIRA, R. de; ARAGÓN, V. A. (org.). Escombros e alternativas: ensino superior na América Latina. Brasília: Editora Universidade de Brasília, 2000, p. 89.

ZAGO, N. Do acesso à permanência no ensino superior: percursos de estudantes universitários de camadas populares. Revista Brasileira de Educação, v. 11, n. 32, p. 231-233, mai./ago. 2006. 
